\title{
Cryoprotective Effects of Ergothioneine and Isoespintanol on Canine Semen
}

\author{
Alexandra Usuga ${ }^{1}$, Irene Tejera ${ }^{1}$, Jorge Gómez ${ }^{2}$, Oliver Restrepo ${ }^{3}$, Benjamín Rojano ${ }^{4} \mathbb{C}$ \\ and Giovanni Restrepo ${ }^{5, *}$ \\ 1 Faculty of Veterinary Medicine and Animal Science, Universidad CES, Medellín 050022, Colombia; \\ ausuga@ces.edu.co (A.U.); tejera.irene@uces.edu.co (I.T.) \\ 2 Faculty of Agricultural Sciences, Politécnico Colombiano Jaime Isaza Cadavid, Medellín 050021, Colombia; \\ jegomez@elpoli.edu.co \\ 3 Nutri-Solla Research Group, Solla S.A., Itagüí 423380, Colombia; orestrepor@solla.com \\ 4 Faculty of Science, Universidad Nacional de Colombia, Medellín 050034, Colombia; brojano@unal.edu.co \\ 5 Faculty of Agricultural Sciences, Universidad Nacional de Colombia, Medellín 050034, Colombia \\ * Correspondence: grestre0@unal.edu.co
}

check for updates

Citation: Usuga, A.; Tejera, I.;

Gómez, J.; Restrepo, O.; Rojano, B.;

Restrepo, G. Cryoprotective Effects of Ergothioneine and Isoespintanol on Canine Semen. Animals 2021, 11, 2757 https://doi.org/10.3390/ani11102757

Academic Editors: Sara Succu and Daniela Bebbere

Received: 1 August 2021

Accepted: 12 September 2021

Published: 22 September 2021

Publisher's Note: MDPI stays neutral with regard to jurisdictional claims in published maps and institutional affiliations.

Copyright: (c) 2021 by the authors. Licensee MDPI, Basel, Switzerland. This article is an open access article distributed under the terms and conditions of the Creative Commons Attribution (CC BY) license (https:/ / creativecommons.org/licenses/by/ $4.0 /)$.
Simple Summary: Cryopreserving dog semen allows the long-term availability of male gametes for future artificial insemination and other assisted reproductive techniques. However, freezing causes irreversible damage to sperm that can affect its ability to fertilize and generate a viable pregnancy. Sperm alterations are partly attributed to oxidation produced by reactive oxygen species (ROS); therefore, antioxidants have been included as extenders for seminal cryopreservation. The unconventional natural antioxidants might reduce deleterious changes in cryopreserved dog sperm; therefore, we evaluated the effects of cryopreservation with the antioxidants ergothioneine and isoespintanol on thawed canine sperm. Various concentrations of both antioxidants improved the movement capacity and structure of thawed spermatozoa, possibly by reducing ROS production. The unconventional antioxidants isoespintanol and ergothioneine improved the quality of cryopreserved canine semen and hence improved assisted canine reproduction.

Abstract: Sperm undergo oxidative stress due to excessive production of reactive oxygen species (ROS) during cryopreservation. Some unconventional natural antioxidants can reduce ROS-induced changes in cryopreserved canine sperm. This study aimed to identify the cryoprotective effects of ergothioneine and isoespintanol on the quality of thawed canine semen. Twelve ejaculates from six dogs were cryopreserved in a tris-yolk extender without (control) or with 50 (E50), 100 (E100), or 150 (E150) $\mu \mathrm{M}$ ergothioneine or 20 (I20), 40 (I40), or 60 (I60) $\mu \mathrm{M}$ isoespintanol. We evaluated the motility and kinetics of thawed sperm using computerized analysis; determined morphology by eosin-nigrosin staining; functional membrane integrity using hypoosmotic tests, and structural membrane and acrosome integrity; mitochondrial membrane potential by fluorescence microscopy; and ROS production by spectrophotometry. Data were statistically analyzed using mixed models and Tukey tests. E100 increased total (60.6\% vs. $49.6 \%)$ and progressive (26.4\% vs. $20.1 \%)$ motility, straight line velocity ( 41.3 vs. $35.9 \mu \mathrm{m} / \mathrm{s})$, and rapid sperm (17.6\% vs. $12.3 \%$ ) compared with controls. However, E150 reduced the numbers of hyperactive sperm. E100, I40, and I60 reduced the abnormal morphology and ROS production, and all concentrations of both antioxidants increased acrosomal integrity. We concluded that ergothioneine and isoespintanol reduce deleterious sperm alterations and oxidative stress in thawed canine semen.

Keywords: antioxidant; cryopreservation; dogs; reactive oxygen species; sperm

\section{Introduction}

Cryopreservation enables the long-term storage of semen, but freezing has been associated with the production of free radicals that can absorb electrons from nucleic 
acids, proteins, and lipids, and cause cell damage [1,2]. Canine semen has an antioxidant system that mainly comprises superoxide dismutase (SOD), glutathione peroxidase (GPx), phospholipid hydroperoxide glutathione peroxidase (PHGPx), glutathione, ergothioneine (ERG), and high levels of L-ascorbic acid in all fractions. However, the canine spermatic fraction lacks activity against lipid peroxidation and catalase compared with semen from other species [3,4]. Therefore, since the development of canine artificial insemination with frozen semen, various known antioxidants such as vitamins $\mathrm{E}$ and $\mathrm{C}$, glutathione, and butylated hydroxytoluene (BHT) have been added to the cryopreservation extenders [5-8]. However, some antioxidants have pro-oxidant effects, depending on their concentration and neighboring molecules $[9,10]$. Thus, unconventional antioxidants such as curcumin, kinetin, and quercetin have attracted interest in terms of improving the quality of thawed canine sperm, increasing its antioxidant capacity, and of expressing genes that modulate reactive oxygen species in sperm [11-13].

Therefore, we investigated the effects of 2-mercaptohistidine trimethylbetaine (ergothioneine (ERG)) and 2-isopropyl-3,6-dimethoxy-5-methylphenol (isoespintanol (ISO)), which have high antioxidant capacity and mitigate alterations in cryopreserved semen from other animal species [14-16]. Ergothioneine is an unusual thio-histidine betaine amino acid and potent antioxidant that is synthesized by microbes such as actinobacteria and some fungi (including mushroom fruiting bodies), but not by animals or plants that acquire it through the diet and soil, respectively [17]. Ergothioneine improves the total motility and viability of cryopreserved ram semen and decreases lipid peroxidation in cryopreserved rooster and ram sperm [14,15]. An important advantage of ERG over other antioxidants is that it does not interfere with the important roles of ROS but acts when oxidative damage becomes excessive [18]. Isoespintanol, extracted from Oxandra cf xylopioides (Annonaceae) leaves, is a free radical scavenger that inhibits lipid peroxidation and strengthens antioxidant enzymatic action. Furthermore, ISO is a more effective antioxidant than its biosynthetic analogue thymol [19], as it regulates mitochondrial activity by decreasing mitochondrial calcium $\left(\mathrm{Ca}^{2+}\right)$ uptake and attenuating permeability transition pore openings in the inner mitochondrial membrane, which is related to mitochondrial swelling and dysfunction [20]. We did not find any other studies in which ERG or ISO were added to frozen canine semen. However, we hypothesized that these antioxidants would reduce reactive oxygen species (ROS) generation in canine semen during cryopreservation. This would consequently reduce structural and functional damage to sperm cells and even modulate their mitochondrial metabolism. Thus, this study aimed to define the effects of ERG and ISO on the thaw quality of thawed canine semen.

\section{Materials and Methods}

\subsection{Sample Collection}

Labrador and Golden Retriever breeds ( $n=6$ each) aged $2-10$ years were housed under similar handling conditions, fed with a commercial concentrate twice daily (morning and afternoon), and given water ad libitum. Before starting the study, the dogs were clinically examined to ensure their health status.

We applied manual stimulation to collect 12 ejaculates from the dogs into cones adapted to $15 \mathrm{~mL}$ plastic tubes, then the three fractions of each ejaculate were separated to minimize the amount of included prostate fluid [21]. The first and third fractions of the ejaculate were discarded, and the second (sperm fraction) was evaluated and cryopreserved.

\subsection{Evaluation of Raw Semen}

The volumes of sperm fractions from the ejaculates were measured using graduated tubes. The sperm cells were counted in one drop of raw semen using an SDM1 photometer (Minitüb GmbH, Tiefenbach, Germany), and sperm motility was assessed using an Eclipse E200 phase contrast microscope (Nikon Inc., Tokyo, Japan), thus obtaining an average of five observation fields $(400 \times)$. The structural membrane integrity (SMI) and abnormal morphology (AM) were evaluated as described below. The raw semen was placed at 
$37^{\circ} \mathrm{C}$ in a water bath in a Tris-based extender (Tris, $2.42 \mathrm{~g}$; citric acid, $1.48 \mathrm{~g}$; fructose, $1.00 \mathrm{~g}$; glycerol, $6.4 \mathrm{~mL}$; gentamicin, $25 \mathrm{mg}$; penicillin; and 50,000 IU / $100 \mathrm{~mL}$ of ultra-pure water) until it reached a sperm count of $25 \times 10^{6} / \mathrm{mL}$. The extender was simultaneously supplemented with $20 \%$ egg yolk diluted 3:1 (v:v) in ultra-pure water and centrifuged at $1600 \times g$ for $100 \mathrm{~min}$.

\subsection{Semen Freezing and Treatment Establishment}

Each ejaculate was divided into seven equal parts and supplemented without (control) or with 50 (E50), 100 (E100), or 150 (E150) $\mu \mathrm{M}$ L-ergothioneine (ERG; Sigma-Aldrich Corp., St. Louis, MO, USA) or $20 \mu \mathrm{M}$ (I20), $40 \mu \mathrm{M}$ (I40), or 60 (I60) $\mu \mathrm{M}$ ISO extracted from Oxandra cf xylopioides leaves [22]. These concentrations were established based on previous studies $[14,16]$. The semen samples were placed at $5{ }^{\circ} \mathrm{C}$ for $60 \mathrm{~min}$, packed in V2 Dual MRS1 0.5-mL straws (IMV Technologies, L'Aigle, France) and placed horizontally for $15 \mathrm{~min}$ in vapor $4 \mathrm{~cm}$ from the surface of liquid nitrogen. The straws were stored in a liquid nitrogen tank at $-196{ }^{\circ} \mathrm{C}$ and placed in a water bath at $37^{\circ} \mathrm{C}$ for $1 \mathrm{~min}$ to evaluate the quality of thawed semen.

\subsection{Post-Thaw Semen Quality Evaluation}

\subsubsection{Sperm Motility and Kinetics}

Seminal motility was assessed using computer-assisted sperm analysis [23]. This consisted of an E200 phase contrast microscope (Nikon Inc., Tokyo, Japan) and a Basler Scout scA780 digital camera (SODA VISION, Woodlands, Singapore) adapted to a computer equipped with SCA motility and concentration (Microptic S.L., Barcelona, Spain) software. The setup comprised a coverslip camera with $20 \times 20 \mathrm{~mm}$, optics in a $\mathrm{pH}(-)$, drop of $7 \mu \mathrm{L}$, dog species, thermal plate at $37^{\circ} \mathrm{C}$, and a particle size of $12-80 \mu \mathrm{m}$. We analyzed total motility (TM), progressive motility (PM), rapid spermatozoa (RAP), straight line velocity (VSL), curvilinear velocity (VCL), average path velocity (VAP), amplitude of lateral head displacement (ALH), beat cross-frequency (BCF), and hyperactive sperm (HYP). At least 500 spermatozoa were evaluated in five observation fields.

\subsubsection{Structural Membrane Integrity (SMI)}

We determined SMI using Live/Dead Kits (Molecular Probes Inc., Eugene, OR, USA) [24]. The membrane-permeable nucleic acid stain SYBR14 and impermeable propidium iodide (PI) label spermatozoa with intact and compromised membranes with green and red fluorescence, respectively. Semen $\left(20 \mu \mathrm{L}\right.$ containing $\sim 20 \times 10^{6}$ spermatozoa $\left./ \mathrm{mL}\right)$ was suspended in Hanks Hepes solution with $1 \%$ bovine serum albumin (BSA), then incubated at $37^{\circ} \mathrm{C}$ for $8 \mathrm{~min}$ with $6 \mathrm{mM}$ SYBR14 followed by $0.48 \mathrm{mM}$ PI. We analyzed 200 spermatozoa using an HBO-E200 fluorescence microscope (Nikon Inc.) with a UV-2A filter. The proportion of spermatozoa with structural membrane integrity (\% SMI) was calculated from the quantity of spermatozoa with green fluorescence.

\subsubsection{Abnormal Morphology (AM)}

We assessed AM using the modified eosin-nigrosin test as follows [18]: One droplet each of semen and eosin-nigrosin (Sigma-Aldrich Corp., St. Louis, MO, USA) were mixed and smeared on a microscope slide, which was then placed on a warming plate at $37^{\circ} \mathrm{C}$. Subsequently, 200 spermatozoa were individually classified as morphologically normal or abnormal using an Eclipse E200 phase contrast microscope.

\subsubsection{Functional Integrity of Membrane (FMI)}

The FMI was assessed using hypo-osmotic swelling (HOS) tests. When exposed to a hypoosmotic solution, functional spermatozoa swell to establish osmotic equilibrium, resulting in typical swelling of the tail [25]. We achieved $100 \mathrm{mOsmol} / \mathrm{L}$ by incubating $100 \mu \mathrm{L}$ of semen with $500 \mu \mathrm{L}$ of a hypo-osmotic sucrose solution $(5.4 \%)$ at $38.5{ }^{\circ} \mathrm{C}$ for 30 min. Thereafter, 200 spermatozoa were evaluated using an Eclipse E200 phase contrast 
microscope. Sperm with tail swelling were considered reactive, and the proportion of sperm with FMI (\% FMI) was calculated.

\subsubsection{Acrosomal Membrane Integrity (AI)}

We evaluated AI using a fluorescein isothiocyanate-conjugated peanut agglutinin (FITC-PNA) probe (Sigma-Aldrich Corp.) [26], which specifically binds to galactosyl $\beta-1,3 \mathrm{~N}$-acetylgalactosamine in acrosomal membranes [27]. These sperm samples were smeared and fixed for $10 \mathrm{~min}$ with $95 \%$ ethanol, dried at room temperature, and then placed in darkness for 30 min with $25 \mu \mathrm{L}$ of FITC-PNA $(5 \mu \mathrm{g} / \mathrm{mL})$ in a phosphate buffer solution (PBS). The smears were then washed with distilled water, and 200 spermatozoa were evaluated using an $\mathrm{HBO}$ fluorescence E200 microscope with a G-2A filter. Sperm with normal or slightly disordered acrosomes were considered intact [28].

\subsubsection{Mitochondria Membrane Potential $(\triangle \Psi M)$}

We used a fluorescence microplate reader and a cationic fluorescent probe JC-1 (Molecular Probes Inc., Waltham, MA, USA) to evaluate $\triangle \Psi M$ [29]. The semen samples were brought to a density of $20 \times 10^{6} \mathrm{sperm} / \mathrm{mL}$, then incubated for $20 \mathrm{~min}$ at $35^{\circ} \mathrm{C}$ with JC-1 in DMSO (2 mM). Green (low $\triangle \Psi M$ ) and red (high $\triangle \Psi M$ ) fluorescence intensities were evaluated as relative fluorescence units (RFUs) using an LS 55 fluorescence microplate spectrometer (PerkinElmer Life and Analytical Sciences Inc., Waltham, MA, USA) at excitation/emission wavelengths of 514/529 and 585/590 nm, respectively. Mitochondrial activity is also expressed as the ratio between high- and low- $\triangle \Psi M$ (red:green).

\subsubsection{Reactive Oxygen Species (ROS) Production}

The semen samples $(30 \mu \mathrm{L})$, buffer solution $(240 \mu \mathrm{L} ; \mathrm{pH} 7.4)$, and $30 \mu \mathrm{L}$ of $40 \mathrm{mM}$ 2,7-dichlorodihydrofluorescein diacetate (H2DCFDA) (Intervet International BV, Boxmeer, The Netherlands) were mixed to produce ROS at $37^{\circ} \mathrm{C}$ [30]. The antioxidant Trolox ${ }^{\circledR}$ (Merck, Darmstadt, Germany) was the reference. The fluorescence intensity was assessed every minute for $80 \mathrm{~min}$ in quadruplicate samples using an LS 55 spectrofluorometer (Perkin Elmer Life and Analytical Sciences Inc., Waltham, MA, USA). The results are shown as relative fluorescence units (RFUs) [31].

\subsection{Statistical Analysis}

We used a completely random model. To evaluate sources of variation, a mixed model was adjusted for each dependent variable (seminal quality parameters). The normality of the data was assessed using Shapiro-Wilk tests. The means were compared using Tukey tests. The level of significance for all assessments was $p<0.05$. All data were analyzed using SAS version 9.2 software (SAS Inst. Inc., Cary, NC, USA).

\section{Results}

\subsection{Raw Semen Quality}

Table 1 shows the quality parameters of the raw canine semen. Volume, concentration, and abnormal sperm morphology were the most variable ( $C V>40 \%)$.

\subsection{Quality of Thawed Semen}

We froze 245 semen straws ( 35 straws per ISO and ERG concentration and control) from 12 ejaculates. Table 2 shows the motility and kinetics of the thawed canine semen. The motility and kinetic parameters of sperm frozen with E100 differed from those of the control and all tested ISO concentrations. Figure 1 shows the morphology and integrity of the plasma and acrosomal membrane of thawed canine spermatozoa. The morphological alterations were reduced by E100 and the highest concentrations of ISO, and all concentrations of both agents increased the acrosomal integrity of thawed canine sperm. 
Table 1. Semen parameters of raw canine semen $(n=12)$.

\begin{tabular}{ccccccc}
\hline & Mean & SD & CV & SEM & Min & Max \\
\hline Volume $(\mathrm{mL})$ & 1.48 & 0.66 & 44.67 & 0.18 & 0.8 & 3 \\
Sperm concentration $\left(10^{6} / \mathrm{mL}\right)$ & 237.54 & 107.96 & 45.45 & 29.94 & 51 & 463 \\
Motility $(\%)$ & 88.46 & 5.55 & 6.27 & 1.54 & 80 & 95 \\
Structural membrane integrity (\%) & 92.31 & 4.57 & 4.95 & 1.27 & 81 & 97 \\
Abnormal morphology $(\%)$ & 18.08 & 7.57 & 41.85 & 2.10 & 7 & 33 \\
Functional membrane integrity (\%) & 88.31 & 6.93 & 7.85 & 1.92 & 76 & 99
\end{tabular}

SD: standard deviation. CV: coefficient of variation. SEM: standard error of the mean. Min: minimum value. Max: maximum value.

Table 2. Motility and kinetics of frozen-thawed canine semen.

\begin{tabular}{|c|c|c|c|c|c|c|c|}
\hline & Control & E50 & E100 & E150 & I20 & I40 & I60 \\
\hline TM & $49.61 \pm 3.90^{b}$ & $56.61 \pm 4.42^{a b}$ & $60.65 \pm 3.56^{a}$ & $54.40 \pm 3.63^{a b}$ & $54.77 \pm 3.57^{\mathrm{ab}}$ & $51.72 \pm 3.48^{b}$ & $52.18 \pm 4.02^{b}$ \\
\hline PM & $20.17 \pm 2.72^{b}$ & $24.73 \pm 3.02^{a b}$ & $26.41 \pm 2.37^{\mathrm{a}}$ & $22.04 \pm 2.59 \mathrm{ab}$ & $20.17 \pm 2.21^{b}$ & $21.41 \pm 2.49^{a b}$ & $20.28 \pm 2.84^{b}$ \\
\hline RAP & $12.31 \pm 1.91^{\mathrm{b}}$ & $16.92 \pm 2.24^{\mathrm{ab}}$ & $17.67 \pm 1.80^{\mathrm{a}}$ & $14.24 \pm 2.03^{a b}$ & $13.09 \pm 1.79^{b}$ & $13.64 \pm 1.87^{\mathrm{ab}}$ & $13.60 \pm 2.11^{a b}$ \\
\hline VCL & $58.39 \pm 2.88^{a b}$ & $60.23 \pm 3.14^{\mathrm{ab}}$ & $62.85 \pm 2.22^{a}$ & $56.00 \pm 2.74^{b}$ & $56.64 \pm 2.68^{b}$ & $55.87 \pm 2.75^{b}$ & $54.37 \pm 3.14^{b}$ \\
\hline VAP & $42.77 \pm 2.59^{a b c}$ & $45.50 \pm 2.8^{a b}$ & $47.97 \pm 2.08^{a}$ & $43.00 \pm 2.38^{a b c}$ & $41.45 \pm 2.48^{b c}$ & $41.85 \pm 2.23^{b c}$ & $39.26 \pm 2.56^{c}$ \\
\hline VSL & $35.97 \pm 2.54 \mathrm{bc}$ & $38.38 \pm 2.88^{a b}$ & $41.35 \pm 1.97^{\mathrm{a}}$ & $37.27 \pm 2.23^{a b c}$ & $35.21 \pm 2.41 \mathrm{bc}$ & $35.77 \pm 2.08^{b c}$ & $32.89 \pm 2.41^{c}$ \\
\hline ALH & $2.34 \pm 0.09^{a}$ & $2.28 \pm 0.11^{\mathrm{a}}$ & $2.31 \pm 0.07^{\mathrm{a}}$ & $2.18 \pm 0.08^{a}$ & $2.30 \pm 0.09^{a}$ & $2.23 \pm 0.08^{a}$ & $2.32 \pm 0.12^{\mathrm{a}}$ \\
\hline $\mathrm{BCF}$ & $7.08 \pm 0.40^{\mathrm{ab}}$ & $7.36 \pm 0.42^{\mathrm{ab}}$ & $7.68 \pm 0.28^{a}$ & $7.34 \pm 0.29 \mathrm{ab}$ & $6.96 \pm 0.35^{a}$ & $7.01 \pm 0.28^{a b}$ & $6.63 \pm 0.39^{b}$ \\
\hline HYP & $2.59 \pm 1.12^{\mathrm{a}}$ & $2.28 \pm 0.84^{\mathrm{ab}}$ & $2.57 \pm 1.07^{\mathrm{a}}$ & $1.08 \pm 0.41^{b}$ & $1.87 \pm 0.76^{\mathrm{ab}}$ & $2.19 \pm 0.74^{\mathrm{ab}}$ & $1.42 \pm 0.00^{\mathrm{ab}}$ \\
\hline
\end{tabular}

TM: total motility. PM: progressive motility (\%). RAP: rapid spermatozoa (\%). VCL: curvilinear velocity ( $\mu \mathrm{m} / \mathrm{s})$. VAP: average path velocity $(\mu \mathrm{m} / \mathrm{s})$. VSL: straight line velocity $(\mu \mathrm{m} / \mathrm{s})$. ALH: amplitude of lateral head displacement $(\mu \mathrm{m})$. BCF: beat cross-frequency $(\mathrm{Hz})$. HYP: hyperactive spermatozoa (\%). E50: ergothioneine at $50 \mu \mathrm{M}$. E100: ergothioneine at $100 \mu \mathrm{M}$. E150: ergothioneine at $150 \mu \mathrm{M}$. I20: isoespintanol at $20 \mu \mathrm{M}$. I40: isoespintanol at $40 \mu \mathrm{M}$. I60: isoespintanol at $60 \mu \mathrm{M}$. TM: total motility (\%). Different letters (a, b, c) within the rows indicate significant statistical difference $(p \leq 0.05)$.

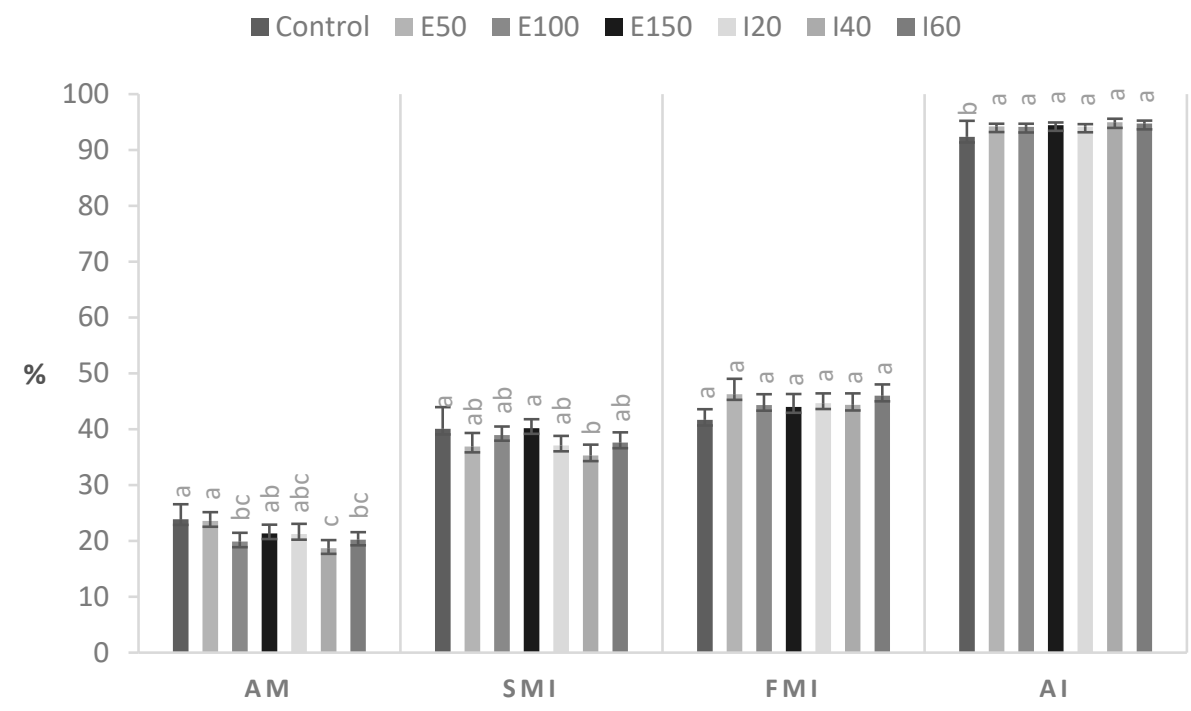

Figure 1. Morphology and membrane integrity of frozen-thawed canine semen. E50: ergothioneine at $50 \mu \mathrm{M}$. E100: ergothioneine at $100 \mu \mathrm{M}$. E150: ergothioneine at $150 \mu \mathrm{M}$. I20: isoespintanol at $20 \mu \mathrm{M}$. I40: isoespintanol at $40 \mu \mathrm{M}$. I60: isoespintanol at $60 \mu \mathrm{M}$. AM: abnormal morphology. SMI: Structural membrane integrity. FMI: Functional membrane integrity. AI: Acrosomal membrane integrity. Bars represent the mean \pm standard error of the mean (SEM). Different letters $(a, b, c)$ between bars indicate significant statistical difference $(p \leq 0.05)$.

The mitochondrial activity of thawed canine sperm is expressed as $\Delta \Psi \mathrm{M}$ (Figure 2), from the green fluorescence of JC-1 monomers (Low- $\Delta \Psi \mathrm{M}$ ), the red fluorescence due to the dimerization of JC-1 (High- $\Delta \Psi \mathrm{M})$, and their relationship (red: green ratio). The mitochondrial membrane potential of cryopreserved canine semen was not affected by 
either antioxidant. Figure 3 shows that E100, I40, and I60 reduced ROS production in thawed canine semen.

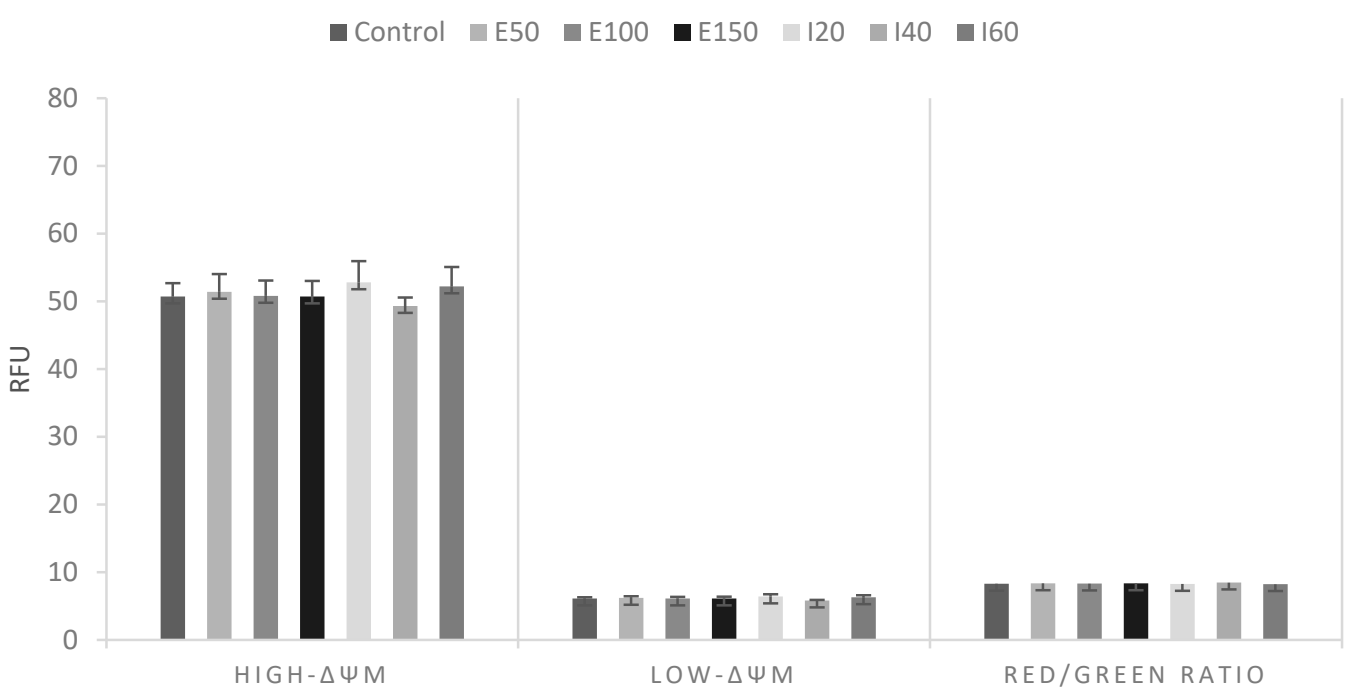

Figure 2. Mitochondrial membrane potential of frozen-thawed canine semen. E50: ergothioneine at $50 \mu \mathrm{M}$. E100: ergothioneine at $100 \mu \mathrm{M}$. E150: ergothioneine at $150 \mu \mathrm{M}$. I20: isoespintanol at $20 \mu \mathrm{M}$. I40: isoespintanol at $40 \mu \mathrm{M}$. I60: isoespintanol at $60 \mu \mathrm{M}$. Low- $\Delta \Psi \mathrm{M}$ : low mitochondrial membrane potential. High- $\triangle \Psi \mathrm{M}$ : high mitochondrial membrane potential. RFU: relative fluorescence units. Bars represent the mean \pm standard error of the mean (SEM). No significant statistical differences were found $(p \geq 0.05)$.

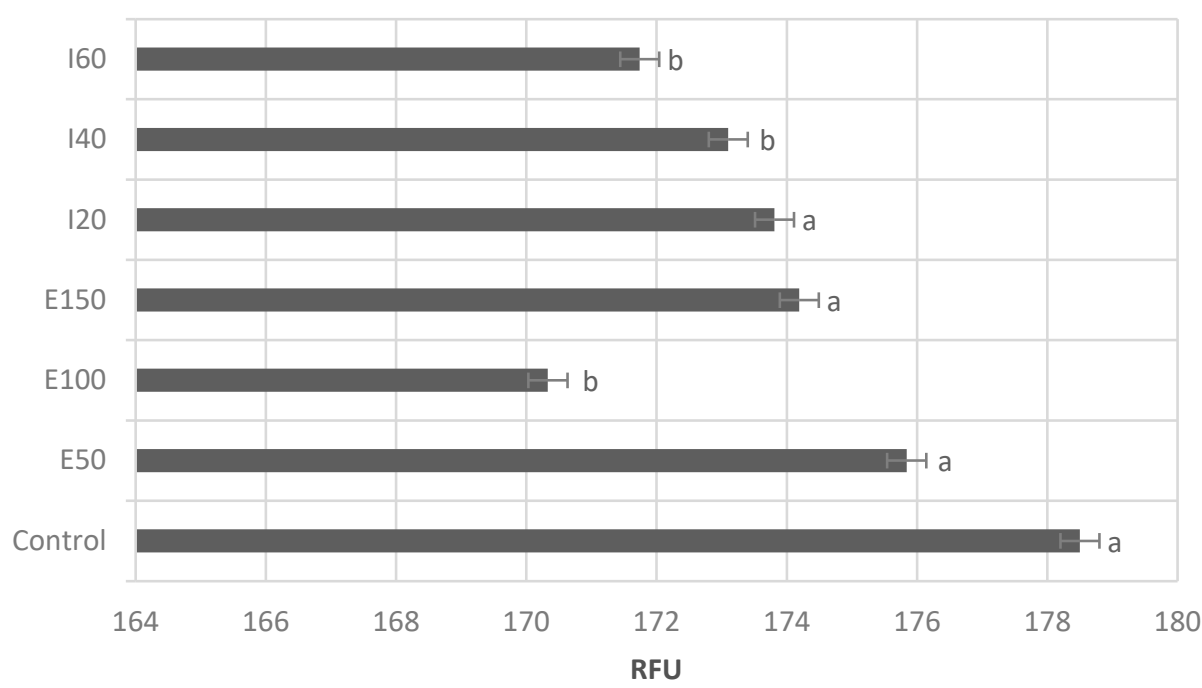

Figure 3. Reactive oxygen species production of frozen-thawed canine semen. E50: ergothioneine at $50 \mu \mathrm{M}$. E100: ergothioneine at $100 \mu \mathrm{M}$. E150: ergothioneine at $150 \mu \mathrm{M}$. I20: isoespintanol at $20 \mu \mathrm{M}$. I40: isoespintanol at $40 \mu \mathrm{M}$. I60: isoespintanol at $60 \mu \mathrm{M}$. RFU: relative fluorescence units. Bars represent the mean \pm standard error of the mean (SEM). Different letters $(a, b)$ between bars indicate significant statistical difference $(p \leq 0.05)$.

\section{Discussion}

Seminal cryopreservation protocols entail distinct steps comprising temperature reduction, dehydration, and freezing in intra- and extracellular medium [32]. This generates increased ROS production, which can indirectly cause oxidative damage to spermatozoa [10]. Furthermore, cryopreservation significantly reduces the availability of antioxidants for cell protection, thus increasing the susceptibility of sperm cells to ROS [33]. Here, we evaluated the abilities of ERG and ISO to reduce ROS generation, oxidative stress, and the 
associated changes during sperm freezing. Adding ERG to the freezing extender positively affected the TM, PM, VSL, and RAP of thawed semen and, consequently, reduced deleterious changes in the morphology and integrity of acrosomes. Ergothioneine improves the movement characteristics of sperm. The supplementing of semen extenders ERG improves the PM, VAP, and the ALH of thawed ram sperm at far higher doses (2 and $4 \mathrm{mM})$ than those used herein $(50,100$, and $150 \mu \mathrm{M})$ [34]. The $\Delta \Psi \mathrm{M}$ of frozen canine spermatozoa was not modified by adding various concentrations of ERG to the extender. This agrees with the effects of even lower concentrations of this antioxidant on rooster semen [14].

We also found that ERG reduces ROS production in thawed canine sperm, indicating a mitigation effect of ERG on oxidative stress during cryopreservation. This could explain the results of other investigations in which ERG improved MT and viability, and reduced lipid peroxidation as well as DNA damage to cryopreserved ram sperm [15,35], although at much higher $(2-6 \mathrm{mM})$ concentrations than those used herein. These findings imply that compared with ram semen, lower concentrations of ERG can cryoprotect canine semen. Studies of 5 and $10 \mathrm{mM}$ ERG did not find any beneficial or detrimental effects on the parameters of thawed ram semen [36]. We also found that ERG did not affect sperm membrane integrity. Different concentrations of ERG negatively affect the fertility rates of thawed rooster semen [14]. Regarding the mechanism of action, ERG has potent intrinsic antioxidant activity against hydroxyl, peroxyl, and peroxynitrite radicals [37]. Ergothioneine can also react with, detoxify, or prevent the formation of singlet oxygen, superoxide, and peroxide reactive species [17].

Isoespintanol decreases mitochondrial calcium $\left(\mathrm{Ca}^{2+}\right)$ uptake and attenuates mitochondrial permeability transition pore openings in the inner mitochondrial membrane of isolated cardiac mitochondria [16]. However, ISO did not affect the $\triangle \Psi M$ of sperm in the present study. Our findings also showed that ISO reduced morphological alterations, protected the acrosome integrity of thawed canine spermatozoa, and significantly reduced ROS production, which might have reduced deleterious oxidative phenomena in sperm structural components. The antioxidant activity of ISO was established using ABTS, DPPH, and TBARS assays, and by its ability to reduce $\mathrm{Fe}^{3+} / \mathrm{TPTZ}$ [31]. Furthermore, ISO at $40 \mu \mathrm{M}$ can reduce ROS production in equine sperm [16]. The antioxidant effects of ISO could be attributed to those of its substituents and to the formation of intra- and intermolecular hydrogen bonds; its antioxidant role might lie in interruption of the second stage of the propagation chain of lipid oxidation by neutralizing lipid radicals (ROO•) [19].

The quality of cryopreserved canine semen has been evaluated [5,38]. However, evaluating the fertility of thawed canine semen in vivo is challenging, since aspects such as the conditions of the genital tract of a bitch in estrus can differently affect semen motility and viability over time [39]. In addition, other factors such as the location of thawed semen deposition, the timing of insemination, the number of inseminations, and prostatic fluid all contribute to fertility $[40,41]$.

This is the first report to describe the effects of ergothioneine and isoespintanol on canine semen, since investigations of the effects of both antioxidants in this species have not been published as far as we can ascertain. Both antioxidants reduced morphological alterations and acrosome damage in thawed canine semen. However, ergothioneine seems to be a more effective antioxidant than isoespintanol for canine semen, as it improved the motility and kinetics and had greater capacity to reduce ROS production in thawed sperm. Future studies should evaluate the antioxidant mechanisms of ERG and ISO in canine semen, as well as their possible effects on the fertilization capacity of sperm in vitro and in vivo.

\section{Conclusions}

Ergothioneine $(100 \mu \mathrm{M})$ and isoespintanol $(60 \mu \mathrm{M})$ reduced deleterious changes in sperm and oxidative stress in thawed canine semen. Ergothioneine is a more effective antioxidant than isoespintanol for canine semen as it improved the motility and kinetics of thawed sperm, probably through its greater capacity to reduce ROS production. 
Author Contributions: Conceptualization, A.U. and G.R.; methodology, A.U., I.T., J.G., B.R., O.R. and G.R.; software, G.R.; formal analysis, A.U. and G.R.; investigation, A.U., I.T. and G.R.; resources, J.G., O.R. and G.R.; data curation, I.T. and G.R.; writing-original draft preparation, A.U., I.T. and G.R.; writing-review and editing, A.U., I.T., J.G., B.R., O.R. and G.R.; project administration, J.G. and G.R.; funding acquisition, J.G. and G.R. All authors have read and agreed to the published version of the manuscript.

Funding: This research was funded by Politécnico Colombiano Jaime Isaza Cadavid, Medellín, Antioquia, Colombia (grant number 2019/00022/001); and the Universidad Nacional de Colombia Medellín Antioquia (grant number 43400).

Institutional Review Board Statement: The study proceeded in accordance with the guidelines of the Declaration of Helsinki and approved by the Ethics Committee of Politécnico Colombiano Jaime Isaza Cadavid, Medellín, Antioquia, Colombia (CEPI 14/09/2018).

Informed Consent Statement: Not applicable.

Data Availability Statement: No new data were created or analyzed in this study. Data sharing is not applicable to this article.

Conflicts of Interest: The authors declare no conflict of interest.

\section{References}

1. Sheikholeslami, S.A.; Soleimanzadeh, A.; Rakhshanpour, A.; Shirani, D. The evaluation of lycopene and cysteamine supplementation effects on sperm and oxidative stress parameters during chilled storage of canine semen. Reprod. Domest. Anim. 2020, 55, 1229-1239. [CrossRef]

2. Cerdeira, J.; Sánchez-Calabuig, M.J.; Pérez-Gutiérrez, J.F.; Hijon, M.; Castaño, C.; Santiago-Moreno, J. Cryopreservation effects on canine sperm morphometric variables and ultrastructure: Comparison between vitrification and conventional freezing. Cryobiology 2020, 95, 164-170. [CrossRef]

3. Strzezek, R.; Koziorowska-Gilun, M.; Kowalówka, M.; Strzezek, J. Characteristics of antioxidant system in dog semen. Pol. J. Vet. Sci. 2009, 12, 55-60. [PubMed]

4. Ball, B.A.; Gravance, C.G.; Medina, V.; Baumber, J.; Liu, I.K.M. Catalase activity in equine semen. Am. J. Vet. Res. 2000, 61, 1026-1030. [CrossRef] [PubMed]

5. Bencharif, D.; Dordas-Perpinya, M. Canine semen cryoconservation: Emerging data over the last 20 years. Reprod. Domest. Anim. 2020, 55, 61-65. [CrossRef]

6. Lecewicz, M.; Strzeżek, R.; Kordan, W.; Majewska, A. Effect of extender supplementation with low-molecular-weight antioxidants on selected quality parameters of cryopreserved canine spermatozoa. J. Vet. Res. 2018, 62, 221-227. [CrossRef]

7. Neagu, V.R.; García, B.M.; Sandoval, C.S.; Rodríguez, A.M.; Ferrusola, C.O.; Fernández, L.G.; Tapia, J.A.; Peña, F.J. Freezing dog semen in presence of the antioxidant butylated hydroxytoluene improves postthaw sperm membrane integrity. Theriogenology 2010, 73, 645-650. [CrossRef] [PubMed]

8. Lucio, C.F.; Silva, L.C.G.; Regazzi, F.M.; Angrimani, D.S.R.; Nichi, M.; Assumpção, M.E.O.; Vannucchi, C.I. Effect of reduced glutathione (GSH) in canine sperm cryopreservation: In vitro and in vivo evaluation. Cryobiology 2016, 72, 135-140. [CrossRef] [PubMed]

9. Carocho, M.; Ferreira, I.C.F.R. A review on antioxidants, prooxidants and related controversy: Natural and synthetic compounds, screening and analysis methodologies and future perspectives. Food Chem. Toxicol. 2013, 51, 15-25. [CrossRef]

10. Michael, A.J.; Alexopoulos, C.; Pontiki, E.A.; Hadjipavlou-Litina, D.J.; Saratsis, P.; Ververidis, H.N.; Boscos, C.M. Quality and reactive oxygen species of extended canine semen after vitamin C supplementation. Theriogenology 2008, 70, 827-835. [CrossRef]

11. Aparnak, P.; Saberivand, A. Effects of curcumin on canine semen parameters and expression of nox 5 gene in cryopreserved spermatozoa. Vet. Res. Forum 2019, 10, 221-226. [CrossRef]

12. Qamar, A.Y.; Fang, X.; Bang, S.; Kim, M.J.; Cho, J. Effects of kinetin supplementation on the post-thaw motility, viability, and structural integrity of dog sperm. Cryobiology 2020, 95, 90-96. [CrossRef]

13. Kawasaki, Y.; Sakurai, D.; Yoshihara, T.; Tsuchida, M.; Harakawa, S.; Suzuki, H. Effect of quercetin on the motility of cryopreserved canine spermatozoa. Cryobiology 2020, 96, 50-54. [CrossRef] [PubMed]

14. Thananurak, P.; Chuaychu-noo, N.; Thélie, A.; Phasuk, Y.; Vongpralub, T.; Blesbois, E. Different concentrations of cysteamine, ergothioneine, and serine modulate quality and fertilizing ability of cryopreserved chicken sperm. Poult. Sci. 2020, 99, 1185-1198. [CrossRef]

15. Najafi, A.; Kia, H.D.; Mohammadi, H.; Najafi, M.H.; Zanganeh, Z.; Sharafi, M.; Martinez-Pastor, F.; Adeldust, H. Different concentrations of cysteamine and ergothioneine improve microscopic and oxidative parameters in ram semen frozen with a soybean lecithin extender. Cryobiology 2014, 69, 68-73. [CrossRef] [PubMed]

16. Restrepo, G.; Rojano, B. Isoespintanol improves the post-thaw quality of stallion semen. Indian J. Anim. Sci. 2018, 88, 50-54. 
17. Borodina, I.; Kenny, L.C.; McCarthy, C.M.; Paramasivan, K.; Pretorius, E.; Roberts, T.J.; Van Der Hoek, S.A.; Kell, D.B. The biology of ergothioneine, an antioxidant nutraceutical. Nutr. Res. Rev. 2020, 33, 190-217. [CrossRef]

18. Halliwell, B.; Cheah, I.K.; Tang, R.M.Y. Ergothioneine-a diet-derived antioxidant with therapeutic potential. FEBS Lett. 2018, 592, 3357-3366. [CrossRef]

19. Rojano, B.; Saez, J.; Schinella, G.; Quijano, J.; Vélez, E.; Gil, A.; Notario, R. Experimental and theoretical determination of the antioxidant properties of isoespintanol (2-isopropyl-3,6-dimethoxy-5-methylphenol). J. Mol. Struct. 2008, 877, 1-6. [CrossRef]

20. González Arbeláez, L.F.; Ciocci Pardo, A.; Fantinelli, J.C.; Rojano, B.; Schinella, G.R.; Mosca, S.M. Isoespintanol, a monoterpene isolated from oxandra cf xylopioides, ameliorates the myocardial ischemia-reperfusion injury by AKT/PKCE/eNOS-dependent pathways. Naunyn. Schmiedebergs. Arch. Pharmacol. 2020, 393, 629-638. [CrossRef] [PubMed]

21. Sánchez-Calabuig, M.J.; Maillo, V.; Beltrán-Breña, P.; de la Fuente Martínez, J.; Galera-Carrillo, S.; Pérez-Gutiérrez, J.F.; PérezCerezales, S. Cryopreservation of canine sperm using egg yolk and soy bean based extenders. Reprod. Biol. 2017, 17, 233-238. [CrossRef]

22. Restrepo, G.B.; Rojano, B.A. Antioxidant activity of isoespintanol and thymol in cryopreserved stallion semen. Rev. Investig. Vet. Peru 2018, 29, 205-216. [CrossRef]

23. Restrepo, G.; Carlos Andrés Madrid, R.; Laura Prieto, R.; Juan Esteban Duque, C.; Alexandra Usuga, S. Freezing of epididymal canine sperm with centrifuged egg yolk. Rev. Investig. Vet. Peru 2017, 28, 876-885. [CrossRef]

24. Gamboa, S.; Rodrigues, A.S.; Henriques, L.; Batista, C.; Ramalho-Santos, J. Seasonal functional relevance of sperm characteristics in equine spermatozoa. Theriogenology 2010, 73, 950-958. [CrossRef]

25. Neild, D.; Chaves, G.; Flores, M.; Mora, N.; Beconi, M.; Agüero, A. Hypoosmotic test in equine spermatozoa. Theriogenology 1999, 51, 721-727. [CrossRef]

26. Rathi, R.; Colenbrander, B.; Bevers, M.M.; Gadella, B.M. Evaluation of in vitro capacitation of stallion spermatozoa. Biol. Reprod. 2001, 65, 462-470. [CrossRef] [PubMed]

27. Mortimer, D.; Curtis, E.F.; Miller, R.G. Specific labelling by peanut agglutinin of the outer acrosomal membrane of the human spermatozoon. J. Reprod. Fertil. 1987, 81, 127-135. [CrossRef]

28. Rajabi-Toustani, R.; Akter, Q.S.; Almadaly, E.A.; Hoshino, Y.; Adachi, H.; Mukoujima, K.; Murase, T. Methodological improvement of fluorescein isothiocyanate peanut agglutinin (FITC-PNA) acrosomal integrity staining for frozenthawed Japanese Black bull spermatozoa. J. Vet. Med. Sci. 2019, 81, 694-702. [CrossRef] [PubMed]

29. Gravance, C.G.; Garner, D.L.; Baumber, J.; Ball, B.A. Assessment of equine sperm mitochondrial function using JC-1. Theriogenology 2000, 53, 1691-1703. [CrossRef]

30. Aitken, R.J.; Smith, T.B.; Lord, T.; Kuczera, L.; Koppers, A.J.; Naumovski, N.; Connaughton, H.; Baker, M.A.; De Iuliis, G.N. On methods for the detection of reactive oxygen species generation by human spermatozoa: Analysis of the cellular responses to catechol oestrogen, lipid aldehyde, menadione and arachidonic acid. Andrology 2013, 1, 192-205. [CrossRef] [PubMed]

31. Rojano, B.; Gaviria, C.; Gil, M.; Saez, J.; Schinella, G.; Tournier, H. Actividad antioxidante del isoespintanol en diferentes medios. Vitae 2008, 15, 173-181.

32. Lucio, C.F.; Regazzi, F.M.; Silva, L.C.G.; Angrimani, D.S.R.; Nichi, M.; Vannucchi, C.I. Oxidative stress at different stages of two-step semen cryopreservation procedures in dogs. Theriogenology 2016, 85, 1568-1575. [CrossRef]

33. Farstad, W. Cryopreservation of canine semen-New challenges. Reprod. Domest. Anim. 2009, 44, 336-341. [CrossRef] [PubMed]

34. Çoyan, K.; Başpinar, N.; Bucak, M.N.; Akalin, P.P. Effects of cysteine and ergothioneine on post-thawed Merino ram sperm and biochemical parameters. Cryobiology 2011, 63, 1-6. [CrossRef] [PubMed]

35. Çoyan, K.; Bucak, M.N.; Başpinar, N.; Taşpinar, M.; Aydos, S. Ergothioneine attenuates the DNA damage of post-thawed Merino ram sperm. Small Rumin. Res. 2012, 106, 165-167. [CrossRef]

36. Yildiz, S.; Öztürkler, Y.; Ari, U.Ç.; Lehimcioğlu, N.C.; Atakişi, E.; Kulaksiz, R. Koç spermasının dondurulması üzerine LErgothionin, N-Asetil sistein ve sisteinin etkileri. Kafkas Univ. Vet. Fak. Derg. 2015, 21, 81-86. [CrossRef]

37. Franzoni, F.; Colognato, R.; Galetta, F.; Laurenza, I.; Barsotti, M.; Di Stefano, R.; Bocchetti, R.; Regoli, F.; Carpi, A.; Balbarini, A.; et al. An in vitro study on the free radical scavenging capacity of ergothioneine: Comparison with reduced glutathione, uric acid and trolox. Biomed. Pharmacother. 2006, 60, 453-457. [CrossRef] [PubMed]

38. Grandhaye, J.; Partyka, A.; Ligocka, Z.; Dudek, A.; Niżański, W.; Jeanpierre, E.; Estienne, A.; Froment, P. Metformin Improves Quality of Post-Thaw Canine Semen. Animal 2020, 10, 287. [CrossRef]

39. Rijsselaere, T.; Van Soom, A.; Van Cruchten, S.; Coryn, M.; Görtz, K.; Maes, D.; de Kruif, A. Sperm distribution in the genital tract of the bitch following artificial insemination in relation to the time of ovulation. Reproduction 2004, 128, 801-811. [CrossRef]

40. Nöthling, J.O.; Shuttleworth, R.; De Haas, K.; Thompson, P.N. Homologous prostatic fluid added to frozen-thawed dog spermatozoa prior to intravaginal insemination of bitches resulted in better fertility than albumin-free TALP. Theriogenology 2005, 64, 975-991. [CrossRef]

41. Thomassen, R.; Sanson, G.; Krogenæs, A.; Fougner, J.A.; Berg, K.A.; Farstad, W. Artificial insemination with frozen semen in dogs: A retrospective study of 10 years using a non-surgical approach. Theriogenology 2006, 66, 1645-1650. [CrossRef] [PubMed] 